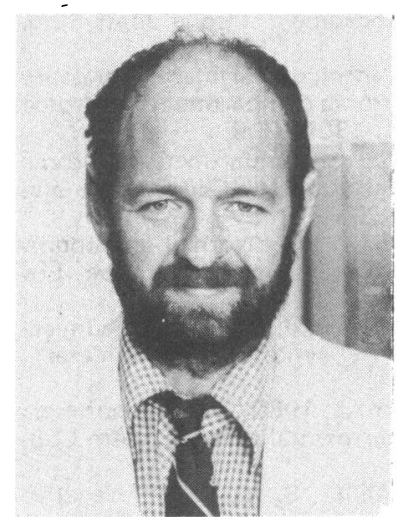

R. J. Maughan

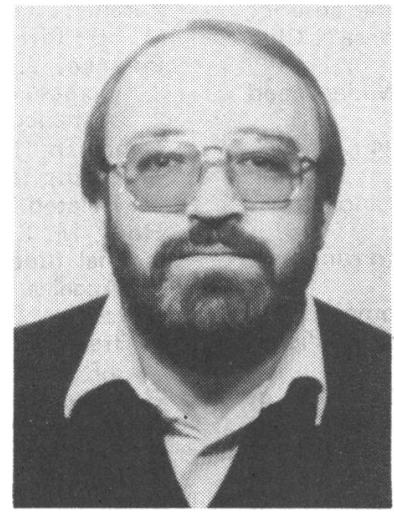

P. H. Whiting

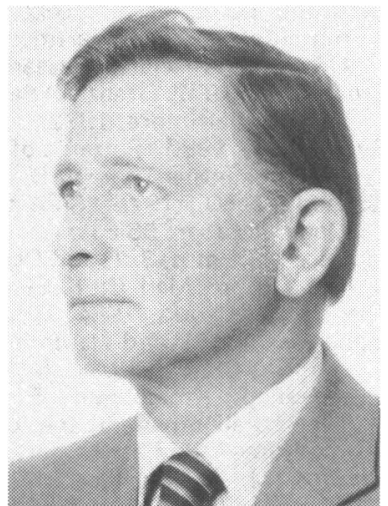

R. J. L. Davidson

\title{
ESTIMATION OF PLASMA VOLUME CHANGES DURING MARATHON RUNNING
}

\author{
R. J. MAUGHAN, BSc, PhD, P. H. WHITING, BSc, PhD* and R. J. L. DAVIDSON, MD, FRCPE, FRC(Path) $\dagger$ \\ Institute of Environmental and Offshore Medicine and Depts. of Chemical Pathology* and Haematologyt, \\ University Medical School, Aberdeen, Scotland
}

\begin{abstract}
Indices of fluid loss have been compared in 47 male runners who completed a competitive marathon (42.2 km) race in times varying from $2 \mathrm{hr} 37 \mathrm{~min}$ to $4 \mathrm{hr} 51 \mathrm{~min}$. Body weight was recorded before and after the race; venous blood samples were collected shortly before and immediately after the race and used for the estimation of haemoglobin concentration, packed cell volume and serum concentration of albumin and total protein. All runners drank a total of $1.4 \mathrm{~L}$ of water during the race. The mean decrease in body weight was $2.1 \pm 0.8 \mathrm{~kg}$ (mean \pm SD), corresponding to $3.0 \pm 1.1 \%$ of initial weight. The decrease in plasma volume (PV), calculated from the haematological parameters, was $6.5 \pm 7.8 \%$ ( $P<0.001$ ). Serum total protein concentration increased $(P<0.001)$ by $10.4 \pm 4.8 \%$ and serum albumin $(P<0.001)$ by $9.6 \pm 5.6 \%$. The increase in serum protein concentration was correlated $(r=0.64, P<0.001)$ with the calculated decrease in $P V$, but was greater $(P<0.001)$ than could be accounted for by the loss of plasma water. The change in PV varied widely between individuals and was unrelated to running speed. The estimated decrease in total body water (5\%) was not different from the decrease in PV (6.5\%), suggesting that water losses were evenly distributed between the intracellular and extracellular compartments.
\end{abstract}

Key words: Marathon running, Fluid loss, Plasma volume.

\section{INTRODUCTION}

In the latter stages of prolonged hard muscular exercise, the circulatory system is placed under stress due to the requirements for a high blood flow to the working muscles to sustain a high metabolic rate and to the skin to promote heat loss (Rowell, 1974). In this situation, a decrease in the blood volume may seriously impair the ability to continue to work. Olsson and Saltin (1971) have shown that losses of fluid corresponding to $3 \%$ of body weight can cause a significant reduction in physical working capacity. The relationships between body weight losses resulting from exercise-induced or heat-induced water loss and changes in blood volume and plasma volume have not, however, been clearly established. Costill (1972) reported that plasma volume decreased by only $2 \%$, corresponding to approximately $60 \mathrm{ml}$, in marathon runners who had lost $7 \%$ of their body weight, equivalent to 4-5 I of fluid. This report was in agreement with the earlier studies of Saltin, who found little change in plasma volume after prolonged exercise (Saltin, 1964; Kozlowski and Saltin, 1964).

\section{Address for correspondence:}

\section{Dr. R. J. Maughan}

Department of Environmental and Occupational Medicine

University Medical School

Foresterhill

Aberdeen, AB9 22D

Scotland
These studies have normally involved only small numbers of subjects; additionally, the studies of marathon runners have used only highly trained athletes. The aim of the present study was to examine the changes in blood volume and plasma volume, calculated from peripheral blood parameters, during marathon competition in runners of widely varying ability. $A$ second aim of the study was to establish whether any relationship existed between the calculated change in plasma volume and the change in body weight which occurred during the race.

\section{MATERIALS AND METHODS}

All measurements were made on participants in the Aberdeen Milk Marathon race, held over the standard distance of $42.2 \mathrm{~km}$ in September, 1982. The race was held on a cool $\left(10-12^{\circ} \mathrm{C}\right)$ day over a relatively flat course. Subjects in this investigation were male competitors selected from among the entrants and were heterogeneous in terms of their physical characteristics, training status and running performance (Table 1). These results were obtained from 47 competitors who completed the course in times ranging from 157 to $291 \mathrm{~min}$.

Venous blood samples $(10 \mathrm{ml})$ were obtained from all subjects $30-60 \mathrm{~min}$ before the start of the race: one aliquot $(4 \mathrm{ml})$ was added to $K_{3}$ EDTA (1 $\mathrm{mg} \mathrm{m}^{-1}$ ) and subsequently used for haematological profiling by a Coulter Counter model $S$ Plus (Coulter Ltd., Harpenden, UK). The remaining blood was allowed to clot in a plain glass tube and the serum separated by centrifugation. Total protein content and albumin in the

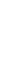


TABLE |

Physical characteristics of the subjects $(n=47)$ and time taken to complete the marathon rece.

\begin{tabular}{lccc}
\hline & Mean & SD & Range \\
\hline Age (yrs) & 34 & 10 & $20-62$ \\
Height $(\mathrm{cm})$ & 176 & 6 & $164-193$ \\
Weight $(\mathrm{kg})$ & 70.7 & 7.9 & $57.4-88.7$ \\
Time $(\mathrm{min})$ & 217 & 32 & $157-291$ \\
\hline
\end{tabular}

serum were estimated using a SMAC autoanalyser (Technicon Ltd., Tarrytown, USA). A second blood sample was collected from each competitor as soon as possible (between $2.4 \mathrm{~min}$ ) after completion of the race and was analysed in the same way. All analyses were completed within a few hours of collection of the samples.

Subjects were weighed wearing only shorts before and after the race, and body weight was recorded to the nearest $10 \mathrm{~g}$. During the race, subjects were required to drink $200 \mathrm{ml}$ of water at each of the 7 feeding stations located at approximately $5.6 \mathrm{~km}$ intervals along the course. No other fluid, nor any solid food, was available to these competitors.

Changes in whole blood volume (WBV), red cell volume (RCV) and plasma volume (PV) were calculated from the values obtained for haemoglobin concentration and packed cell volume (PCV) before and after the race, using the calculations described by Dill and Costill (1974). The equation of Beaumont (1972) which has been used to calculate changes in PV on the basis of haematocrit values alone is not applicable as it depends upon a constant red cell volume being maintained.

\section{RESULTS}

As might be expected in such a heterogeneous group of subjects, considerable inter-individual variability was observed in all parameters measured. All subjects suffered a decrease in body weight during the race, the mean weight loss being $2.09 \pm 0.77 \mathrm{~kg}$, corresponding to $3.0 \pm 1.1 \%$ of the pre-race body weight. The inter-individual variation in weight loss was large, ranging from $1.0 \%$ to $5.9 \%$ of the pre-race weight. These values were not corrected for (a) the $1.4 \mathrm{~kg}$ of water ingested during the race because it was not possible to estimate the fraction which remained unabsorbed in the gut, or (b) the weight lost from $\mathrm{CO}_{2}-\mathrm{O}_{2}$ exchange in the lungs, as a single correction factor could not reasonably be applied to such a diverse subject group. The weight loss, whether in absolute terms or as a percentage of body weight, was unrelated to the time taken to complete the race.

Small, but significant, increases in both haemoglobin concentration and PCV occurred during the race. The haemoglobin concentration increased from $145 \pm 9$ to $149 \pm 11 \mathrm{~g} . \Gamma^{1}$ ( $P<0.001$ ); $P C V$ increased from $42.6 \pm 2.2$ to $45.0 \pm 3.2 \%$ $(P<0.001)$. The calculated decrease in WBV was $2.4 \pm 4.7 \%$ (P $<0.002)$; RCV increased (P $<0.001)$ by $3.2 \pm 3.7 \%$; PV decreased $(P<0.001)$ by $6.5 \pm 7.8 \%$ (Table II).

TABLE II

Percentage chenes in the components of blood volume calculated from pro-race and post-race hapmoglobin and PCV values as deseribed by Dill and Costill (1974).

\begin{tabular}{lccc}
\hline & Mean & SD & Range \\
\hline Blood Volume & -2.4 & 4.7 & $-13.2-+16.7$ \\
Red Cell Volume & +3.2 & 3.7 & $-4.1-+16.5$ \\
Plasma Volume & -6.5 & 7.8 & $-24.7-+10.7$ \\
\hline
\end{tabular}

Serum protein concentration increased $(P<0.001)$ by
$10.4 \pm 4.8 \%$ from $67 \pm 3$ to $72 \pm 14 \mathrm{~g} . \Gamma^{1}$. Serum albumin concentration increased (P $<0.001$ ) by $9.6 \pm 5.6 \%$, from $47 \pm 2$ to $51 \pm 3 \mathrm{~g} . \Gamma^{1}$. The increase in serum protein concentration which took place was greater $(P<0.001)$ than can be accounted for by the decrease in PV alone, and implies a movement of protein into the circulation. Some of the additional protein may be in the form of haemoglobin, which appears in the plasma as a result of intravascular haemolysis, but this is unlikely to account for a significant proportion of the total protein content.

There was a close correlation between the calculated decrease in $\mathrm{PV}$ and the increase in serum protein concentration $(r=0.64, P<0.001 ;$ Fig. 1$)$. Since the changes in serum total protein and albumin concentration were closely related $(r=$ $0.74, P<0.001)$, it is not surprising that a similar relationship was also seen to exist between the decrease in PV and the increase in albumin concentration $(r=0.58, P<0.001)$.

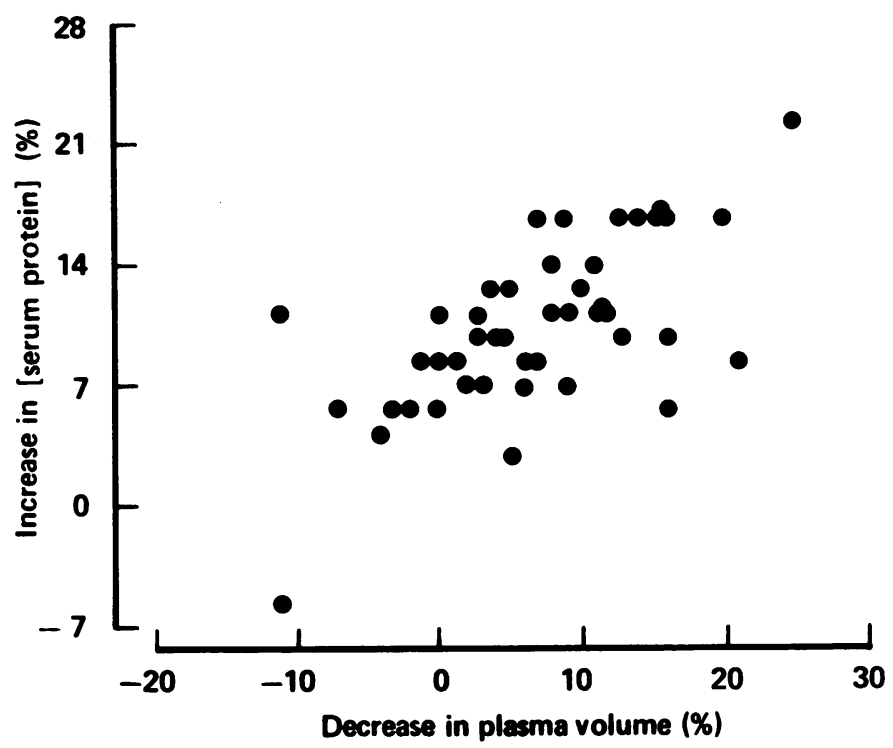

Fig. 1: A significant ( $r=0.64, P<0.001$ ) relationship was observed to exist between the percentage change in serum total protein concentration and the calculated decrease in plasma volume. The relationship is best described by the equation: $y=0.39 x+7.8$

The percentage decrease in body weight was significantly correlated with the increases in both serum protein $(r=0.44$, $P<0.01$; Fig. 2) and serum albumin $(r=0.32, P<0.05$; Fig. 3) concentrations and also with the decrease in $P V(r=$ $0.54, P<0.001$; Fig. 4).

\section{DISCUSSION}

It is apparent from the loss of body weight suffered by these runners that substantial amounts of body water had been lost, in spite of the relatively cool environmental conditions. Of particular note is the inter-individual variability in the extent of the weight loss, which ranged from $1 \%$ to almost $6 \%$ of the initial body weight. Such wide differences cannot be adequately explained on the basis of the variations in work rate or time taken to complete the race, but must also reflect major differences between individuals in their degree of peripheral vasodilatation and rate of sweat secretion.

The relationship between the calculated decrease in PV and the decrease in body weight was highly significant (Fig. 4), but within this relationship, considerable variation between individuals was seen. The mean decrease in PV was 6.5\%, compared with a mean loss of body weight of $3.0 \%$. These figures can be interpreted as indicating that proportionately more fluid is lost from the intracellular compartment than from the extracellular space, of which the plasma is representa- 


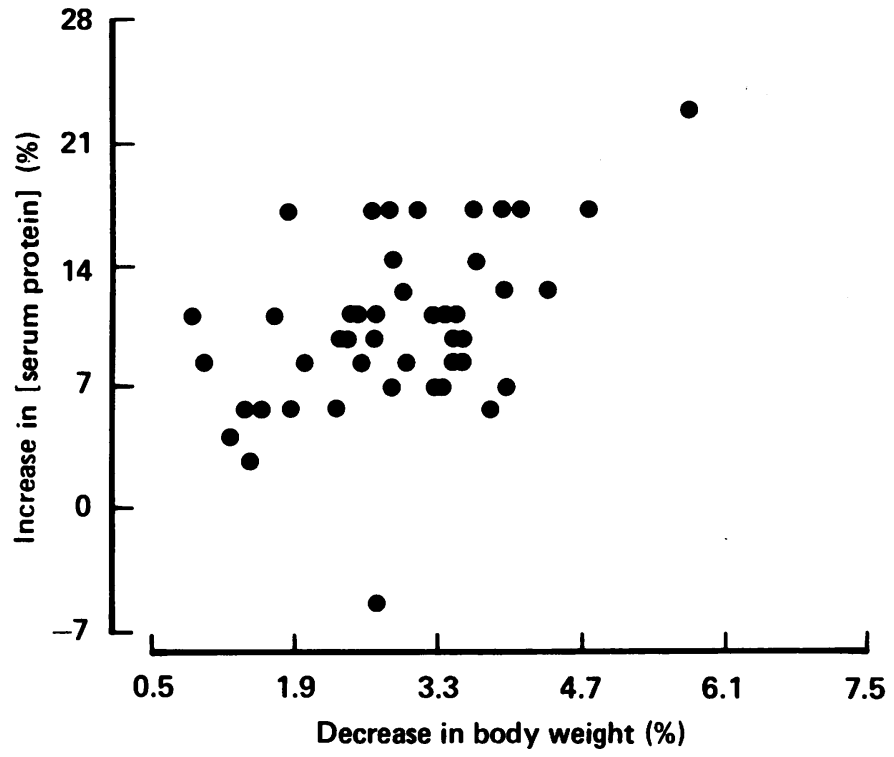

Fig. 2: A weak but statistically significant $(r=0.44, P<0.01)$ relationship existed between the change in serum protein concentration and the loss of body weight. The line of best fit is given by the equation: $y=2.18 x+4.0$.

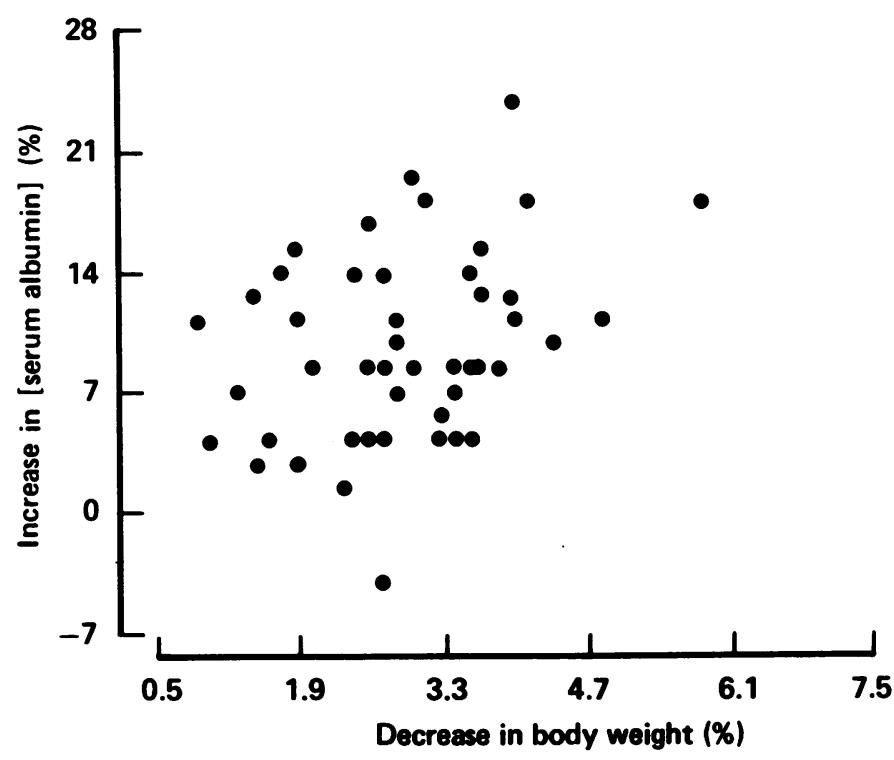

Fig. 3: The relationship between the change in serum albumin concentration and the decrease in body weight was weak, but statistically significant $(r=0.32, P<0.05)$, and is described by the equation: $v=1.73 x+4.6$

tive. However, for a $71 \mathrm{~kg}$ man, whose total body water space represents some $60 \%$ of body weight (Åstrand and Rodahl, 1977), total body water weighs $42.6 \mathrm{~kg}$ : loss of $3.0 \%$ of body weight, if this is all water, will decrease the body water to $40.5 \mathrm{~kg}$. The percentage change in total body water content is thus $5.0 \%$. The calculated decrease in PV is not greatly different from the decrease in total body water, allowing for the errors in the assessment of weight loss, the assumption of a constant body water content for all subjects and the errors in the calculation of the change in PV. This suggests that loss of water from intracellular and extracellular compartments is similar. This does not support previous observations that the water lost as sweat during prolonged exercise is derived primarily from the intracellular compartment (Kozlowski and Saltin, 1964; Costill, 1972) or the extracellular compartment (Adolph, 1947; Costill and Fink, 1974).

Support for the suggestion that the plasma volume might be maintained in spite of substantial losses of body water

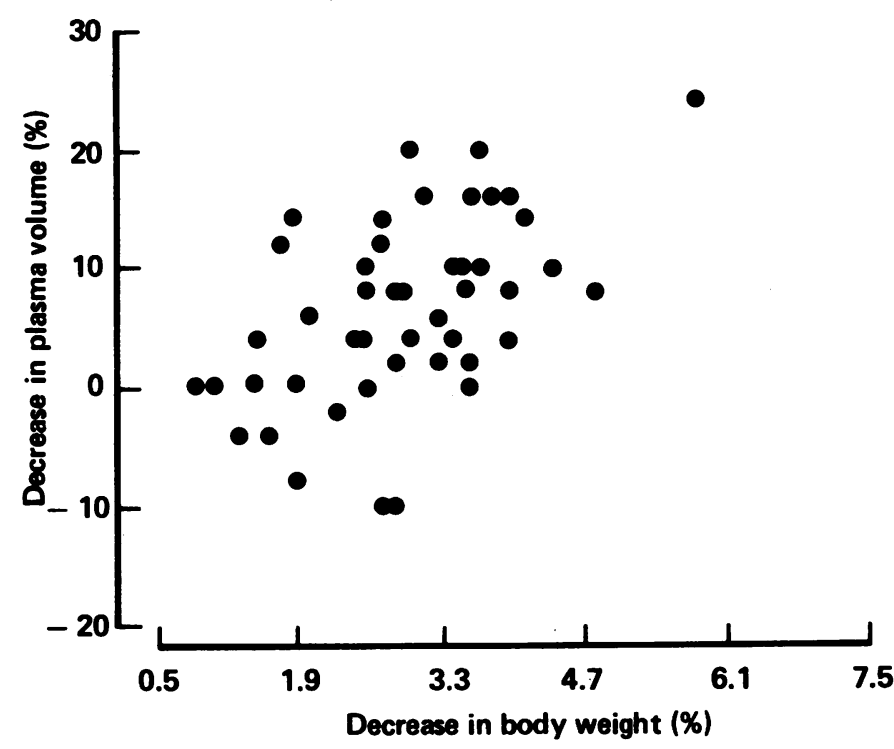

Fig. 4: The change in plasma volume was correlated with the decrease in body weight $(r=0.54, P<0.001)$. The line of best fit is given by the equation: $y=4.16 x+5.6$.

comes from a report by Costill (1972) who observed only small changes (approximately $2 \%$ ) in the plasma volume after a marathon race which resulted in body weight being reduced by $8 \%$ of the pre-race value. Olsson and Saltin (1971) also considered that the water lost during exercise was derived from the intracellular compartment rather than from the plasma.

In contrast to these results, Dill and Costill (1974) observed a decrease in plasma volume of $12 \%$ in runners whose body weight had decreased by $4 \%$ of its pre-exercise value. Comparable changes in plasma volume were reported by Wells et al (1982) who found a decrease in plasma volume of $8 \%$ in female marathon runners and a $13 \%$ decrease in male runners: they did not, however, record the weight loss of their subjects.

The wide variability in the relationship between the decrease in body weight and the calculated decrease in PV which was observed in the present study does, however, suggest that water losses from the major fluid compartments do not occur in fixed proportions. This variability precludes the estimation of changes in PV from measurements of body weight loss. Harrison et al (1982) have pointed out the problems associated with the use of the formula described by Dill and Costill (1974) to calculate changes in plasma volume. The calculations assume that the peripheral haematocrit accurately reflects the whole body haematocrit in both the pre-race and post-race conditions; small changes in the distribution of the red cell mass have a large influence on apparent changes in blood volume. These findings indicate the limitations of using both body weight, which takes no account of body fluid compartments, and changes in plasma volume, which may be unrelated to cellular water loss, as indices of dehydration.

In the past, changes in the total protein content of plasma were commonly used to assess dehydration, on the assumption that significant movements of protein across the vascular endothelium did not occur in the short interval during which exercise studies are normally conducted. It became apparent from the study of Dill and Costill (1974), however, that substantial protein shifts could occur during exercise. In the present study. the serum albumin and total protein concentrations increased by $10.4 \%$ and $9.6 \%$ respectively, compared with a calculated decrease in PV of $6.5 \%$. From this, it is apparent that a movement of protein into the vascular space has occurred. 
In contrast, Dill and Costill (1974) reported that protein was lost from the circulation during prolonged running: they observed protein losses from the circulation equivalent to $6 \%$ of the initial concentration. Viru and Körge (1971) had earlier reported no change in the plasma protein concentration during marathon running. In agreement with the present results, however, Wells et al (1982) observed an increase in plasma protein concentration following a marathon race, the increase being greater than that which could be attributed solely to the decrease in PV. Maron et al (1975) also observed a similar response and calculated, on the basis of results obtained from six marathon runners, that approximately $27 \mathrm{~g}$ of protein had entered the circulation during the race. From the conflicting nature of these results, it is apparent that several factors may be involved in the regulation of the plasma protein content during prolonged running and that the changes which are observed are not simply the result of changes in PV. As the subjects in the present study represented a wide range of levels of fitness and running speed, it is unlikely that either of these factors is of major significance. It seems probable that variations in environmental conditions, such as temperature and humidity, and differences in the peripheral circulatory response of the subjects may be important contributory factors to the differences recorded in different studies. The present study also illustrates the large variability in the changes in body water which occur in response to marathon running. Some of the changes in PV calculated on the basis of changes in PCV and haemoglobin concentration are so large as to appear to be in error, but this cannot be stated with certainty in the absence of direct measurements.

\section{ACKNOWLEDGEMENTS}

This study was supported by a grant from Revlon Health Care (UK) Ltd. Dr. R. J. Maughan is supported by a grant from Shell (UK) Exploration and Production Ltd.

\section{References}

Adolph, E. F., 1974 "Blood changes in dehydration" In: Physiology of Man in the Desert. pp. 160-171. E. F. Adolph and Associates. London and New York: Interscience Publishers.

Astrand, P. O. and Rodahl, K., 1977. A Textbook of Work Physiology. McGraw-Hill Book Co., New York.

Beaumont, W. Van, Greenleaf, J. E. and Johos, L., 1972 “Disproportional changes in haematocrit, plasma volume and proteins during exercise and bed rest". J.Appl.Physiol. 33: 55-61.

Costill, D. L., 1972 "Physiology of marathon running". JAMA 221 . 1024-1029.

Costill, D. L. and Fink, W. J., 1974 "Plasma volume changes following exercise and thermal dehydration". J.Appl.Physiol. 37: 521-525.

Dill, D. B. and Costill, D. L., 1974 "Calculation of percentage changes in volumes of blood, plasma and red cells in dehydration". J Appl. Physiol. 37: 247-248.

Harrison, M. H., Graveney, M. J. and Cochran, L. A., 1982 "Some sources of error in the calculation of relative change in plasma volume". Eur.J.Appl.Physiol. 50: 13-21.

Kozlowski, S. and Saltin, B., 1964 "Effect of sweat loss on body fluids". J.Appl Physiol. 19: $1119-1124$.

Maron, M. B., Horvath, S. M. and Wilkerson, J. E., 1975 "Acute blood biochemical alterations in response to marathon running". Eur.J. Appl.Physiol. 34: 173-181.

Olsson, K. E. and Saltin, B., 1971 "Diet and fluids in training and competition". Scand.J.Rehab.Med. 3: 31-38.

Rowell, L. B., 1974 "Human cardiovascular adjustments to exercise and thermal stress". Physiol.Rev. 54: 75-159.

Saltin, B., 1964 "Aerobic work capacity and circulation at exercise in man: With special reference to the effect of prolonged exercise and/ or heat exposure". Acta Physiol.Scand. 62 (Suppl. 230): 1-52.

Viru, A. and Korge, P., 1971 "Metabolic processes and adrenocortical activity during marathon races"'. Int.Z.angew.Physiol. 29: 173-183.

Wells, C. L., Stern, J. R. and Hecht, L. H., 1982 "Haematological changes following a marathon race in male and female runners". Eur.J.Appl.Physiol. 48: 41-49.

I took over his teaching duties in the Physical Education Department in 1958, and found it hard to succeed him in his job. He devoted his time to the clinical work of the colleges, which were growing fast, and in the mid-1960's established the Student Health Centre for the newly formed University of Technology, where he worked until his retirement in 1972. He was keenly interested in the sporting life of the Colleges and University, and his reduction of a dislocated shoulder immediately after its occurrence was masterly. He was always available for emergencies, at all hours of the day and night, and usually to be found on the touch line or edge of the track whenever there was a match. He joined the British Association of Sport and Medicine in 1961, and gave us his support until he moved out of Loughborough in 1972. Although I had not seen him for several years, I feel a deep personal loss, and we extend our sincerest sympathy to his wife, Dr. Helen Smith, and to his family. 